


\title{
GEODOC -
}

The GRID Document File, Record Structure and Data

Element Description

T. Trippe, V. White, F. Henderson and

S. Phillips

6 Nov 1975

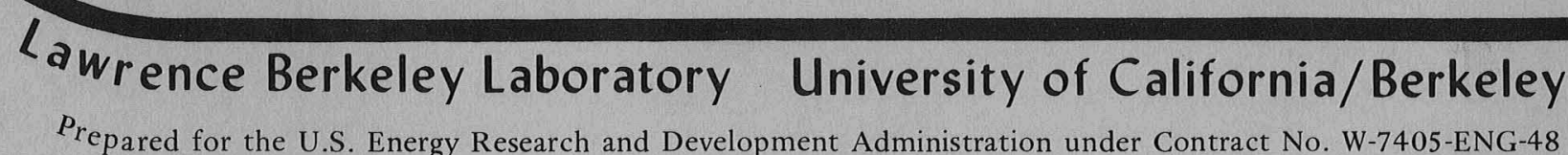

\section{For Reference}


Printed in the United States of America Available from

National Technical Information Service U.S. Department of Commerce 5285 Port Royal Road Springfield, Virginia 22161

Price: Printed Copy $\$ 5.00$; Microfiche $\$ 2.25$ 


\section{OEODOC - The ORID Document File, Record Structure and Dato Element Description}

T. G. Trippe, V. A. White, F. B. Henderson III, and S. L. Phillips

The purpose of this report is to describe the information structure of the GEODOC file, the document file of the National Geothermal Information Resource.

\section{THE GEODOC FILE}

GEODOC is a computer based file which contains the descriptive cataloging and indexing information for all documents processed by the National Geothermal Information Resource Group. This file (along with other GRID files) is managed by DBMS, the Berkeley Data Base Management System(1). Input for the system is prepared using the IRATE Text Editing System ${ }^{(2.3)}$ with its extended (12 bit) character set ${ }^{(4)}$, or punched cards.

\section{GEODOC RECORD STRUCTURE}

Each record in the GEODOC file contains the descriptive cataloging, abstracting, and indexing information corresponding to a single document. The information within a given record is subdivided into "data clements". Table I lists the defiritions of all the data elements which may appear in a GEODOC record. Some data elements (e.g., autrior's name) can occur repeatedly within one record. An " $m$ " in the third column of Table I indicates that such multiple occurrences are allowed.

The "LBL tag" for each data element is shown in the left hand column of Table I. These tags are used to label the data elenients within a record.

The data elements bear certain hierarchical relationships to each other; that is, some data elements are subordinate to, or, conversely, parents of, othars. As will be seen, these relationships reflect certain natural relationships which exist between the various data elements. Figure 1 is a diagram of this hierarchical structure. The structure is also indicated in Table $I$ by indenting the tag names of subordinate data elements and placing them after their parents.

The data elements may be input to the system in any order except that subordinate dato elements must follow the occurrence of their parent with which they are associated. The use of this structure is made clearer in the examples given in the GEODOC INPUT section below.

\section{INIS COMPATIBILITY}

We have based our descriptive cataloging techniques on those of the International Nuclear Information System (INIS) of the International Atomic Energy Agency (IAEA). We have depended heavily on their excellent documentation, the IAEA-INIS series, which 
is referenced throughout this text.

In an effort to make this document stand alone, at least for those cases currently being handled by GRID, we have borrowed heavily from the INIS documentation, in some cases summarizing or even copying blocks of text. The presence of an INIS tag number after the titles in the Data. Element Definitions section below indicates such a treatment.

The GEODOC data elements were selected to correspand as closely as possible with those used by INIS. This facilitates future information exchange with other data bases, (e.g.. the ERDA Energy Data Base at Oak Ridge), and also permits us to use the existing INIS descriptive cataloging method(5).

An INIS tog is shown in Table I for those data elements whose internal format is identical or almost identical to the INIS format(5). This is shown primarily for convenience in referencing INIS documentation.

\section{GEODOC INPUT}

The information for a GEODOC record is entered into the system by specifying the "dato element value" (i.e., the contents) of each data element using DBMS(1) input statements of the form:

$$
\text { TAG.m = "data element value"; }
$$

where TAG is an LBL tag (from Table I). The tag is followed by a period and an "occurrence number" $(\mathrm{m})$ which specifies that the $\mathrm{m}^{\text {th }}$ value of TAG is being entered. If $(. m)$ is omitted, $(.1)$ is assumed; if the $($.$) is present but the (m)$ is omitted, then $(m)$ is assumed to be the next available occurrence number. An equal sign precedes the data element value and a semi-colon must follow it. For example, a series of three authors names is written:

AU.1=Norikova, M.;

AU.2 = Dorikens-Vanpraet, L.;

AU.3=Bobrowski, C.:

It is not neccessary to write these on separate lines because blanks and new lines foilowing semi-colons are ignored. Also, os is described above, it is unnecessary to input the occurrence number explicitly. Thus the three author names could be input as:

$A U=$ Norikova, M.; $A U .=$ Dorikens-Vanpraet, L.; $A U .=B o b r o w s k i, C . ;$

This input can be further simplified by omitting the two appearances of "AU. =". This is because when the input processor encounters a semi-colon which is not followed by a valid LBL-tag, it assumes "TAG.=", where TAG is the last valid tag processed. Thus the three names can be input as:

$A U=$ Norikova, M.; Dorikens-Vanpraet, L.; Bobrowski, C.;

This last input form is the simplest method for inputting multiple values of data elements. A more complete example is now given for the data elements under AUTHORS. The simplest way to input multiple authors, an author note, different affiliations and af filiation codes is as follows: 


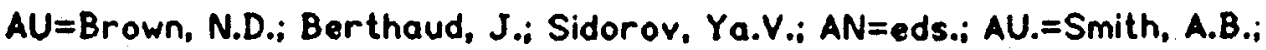

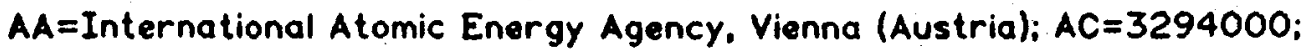

$A U=$ Mueller, F.; Swoboda, K.;

$A A=$ Oesterreichische Studiengesellschaft fur Atomenergie G.m.b.H., Seibersdorf. Forschungszentrum; $A C=4853000$;.

This is interpreted by the input processor to be:

AUTHORS.1;

AU.1=Brown, N.D.;

AU.2=Berthaud, J.;

$A L \cdot 3=$ Sidorov, Ya.V: AN=eds.;

AU.4=Smith, A. B.;

$A A=$ International Atomic Energy Agency, Vienna (Austria); $A C=3294000$

\section{AUTHORS.2;}

AU.1=Mueller, $F_{\text {.; }}$

AU.2=Swoboda, K.;

$A A=$ Oesterreichische Studiengesellschaft fur Atomenergie G.m.b.H.

Seibersodorf. Forschungszentrum; $A C=4853000$;.

This longer form could also be used to input the information.

Note that the dato elements AUTHORS is not written in the simpler input form. The input processor inserts it because it must be present before any of its subordinate data elements can be input. Automatic insertion of the AUTHORS data element can be done because it is a "pure node" dota element, i.e., a data element which contains no value. The purpose of pure node data elements is to link together groups of subordinate dato elements. The first AUTHORS node in the above example links the authors Brown, Berthaud, Sidorov and Smith with their affiliation, the International Atomic Energy Agency. The second AUTHORS node links the authors Mueller and Swoboda with a different affiliation.

Some lower level data elements appear in the above example. The author note $A N=e d s . ;$ is subordinate to AU.3 of AUTHORS.1. Each affiliation AA has a subordinate affiliation code AC. the seven digit INIS corporate code (6).

Note that the period following $A U$ in $A U .=S m i t h, A . B . ;$ is necessary. It causes Smith to be input as the fourth occurrence of $A U$ in AUTHORS.1. If AU without a period had been used, Smith would have been input as AU.1. Since an AU.1 (Brown) already existed in AUTHORS.1, a new. AUTHORS node would erroneously have been created.

To summarize the conventions introduced above, let TAG be any data element tag.

a) TAG always means TAG.1

b) TAG. always means TAG.n where $n$ is the next available occurrence number.

c). The absence of any valid tag following a semi-colon always means TAG.n where TAG is the last valid tag input, and $n$ is as above.

d) Subordinate data elements must follow the parent to which they are linked and precede the next occurrence of their parent. 
e) Pure node parent data elements will be created automatically whenever required by the input of subordinate data elements.

\section{DATA ELEMENT DEFINITIONS}

The data elements and brief definitions are listed in Table I. This section gives a detailed description of each data element. We rely heavily upon the INIS descriptive cataloging rules $^{(5)}$, hereafter referred to as the INIS rules, for our descriptions.

Short Code (SC) one per record, mandatory.

This is a unique identifier for a document. It is composed of the first authors last name, a blank, a two digit year and, if necessary, a letter for uniqueness. E.g.,

$S C=$ Valf ells 75 ; or

$\mathrm{SC}=$ Smith 69E;

The sequence for the uniqueness letter is "blank", B, C, etc. A is not used. The last name should be identical with that given in Authors Name (AU). Use Anon. (e.g.. SC=Anon. 75F) for any document which has no personal authors.

Record Type (TY) INIS-008 one per record, mandatory.

This is the INIS tag 008 information:

Type of Record/Bibliographic Levels/Literary Indicator

E.g., $T Y=R / A M / K$; or $T Y=J / A S$;. The following is a brief summary. See the INIS rules(5) for details. The allowed values for the components of TY are:

Type of Document - one of the following.

$$
\begin{aligned}
& \text { B - book } \\
& \text { C - collection } \\
& D \text { - drawing } \\
& \text { F - film } \\
& \text { - map } \\
& H \text { - phonorecord } \\
& J \text { - journal article } \\
& P \text { - patent } \\
& R \text { - report } \\
& T \text { - computer medium }
\end{aligned}
$$

Bibliographic Levels - a combination of the letters $A, M, S$ and $C$ defined as follows:

A - Analytic - only works not published separately but as part of a larger bibliographic entity (cannot be used alone); e.g.. chapter of a book, journal article, individual papers in conference proceedings.

M - Monograph - publications which ore non-serial because they are complete at the time they are issued or are to be issued in a known number of parts, e.9., reports, patents, pre-conference papers, books or monographs.

$S$ - Serial - publications issued in successive parts and intended to be continued indefinitely (cannot be used alone), e:g. periodicals, journals, proceedings, numbered monographic series.

C - Collective - various documents or other types of records gathered together and cataloged as a single unit, e.g., samples of microfiche. a folder bearing a title representative of its contents and 


\section{0,04403249}

containing various loose-leaf sheets.

Allowed combinations of $A, M, S$ and $C$ follow, along with examples of their uses.

M-- book, patent, pre-conference paper, report, encyclopedia, handbook

C - - collection of individually titled drawings

AM -- article in an encyclopedia, chapter of a book or report, conference paper in a bound set of proceedings

AS - - article in a journal

MC -- report or brochure or patent in a collection

MS - - book in a series

AMC - chapter of a report in a collection

AMS - chapter of a book in a series, conference paper from a proceedings book, which is part of a proceedings series.

Literary-Indicator as many as are applicable.

$K$ - conference (mandatory, see tag COT below)

$L$ - dictionary, encyclopedia or glossary

$N$ - numerical data

$\mathbf{U}$ - thesis (mandatory)

$H$ - defines a standard or specification

$Z$ - bibliography

Y - progress report (mandatory)

$E$ - abstract or "short communication" (mandatory, see tag $N$ below)

\section{Descriptive Cataloging Node (DES-CAT)}

DES-CAT is a pure node data element, i.e., it contains no value; all its information is carried in the data elements subordinate to $i t$. This node contains all of the data elements required for one level of descriptive cataloging. It is essentially equivalent to one INIS worksheet. There must be one DES-CAT node for each bibliographic level (i.e., one for each letter in the "Bibliographic Levels" part of TY described abovel. The nodes must appear in the same order as the letters in TY, i.e., in order of increasing bibliographic level. E.g., for a paper published in a conference proceedings report, we would have



where BL is the "Bibliographic Level Indicator" described below. The data element name DES-CAT is not normally written in the input. It is inserted automaticaliy when BL is input.

For each bibliographic level and type of record, Appendix I, the "Matrix of Bibliographic Data Elements," indicates which of the data elements are required (X). required if 
present (P), optional (O) or forbidden (blank).

\section{Data Elements of the DES-CAT Node:}

Blbllographic Level Indicator (BL) INIS-008 Subordinate to DES-CAT.

There must be one BL per DES-CAT node. This can have one of the four possible values $A, M, S$, or $C$ as defined in the record type (TY) data element above.

Primary Title (PT) INIS-200 Subordinate to DES-CAT.

This is the title in English (translate if necessary). One is required on each level except $S$ (serial). Serial titles and subtitles are always entered as original title (OT) and original subtitle (OS); they are not translated. Capitalize the first letter and proper nouns only.

If the document is a chapter in a book, enter the chapter title here on level $A$ and the book title on level $M$. If the chapter has both an actual title and something of the form "Chapter 5", enter the actual title here and enter the "Chapter 5" as the primary subtitle (PS) below. If no actual title exists enter the "Chapter $5^{\prime \prime}$ here as the primary title (PT). The same principles apply to "Part 3". "Section 5", or any other such subdivision. Capitalize the first letter, translate to English and convert the numerals to Arabic if necessary, e.g., "second chapter" become "Chapter 2".

Primary Subtitle (PS) INIS-201 Subordinate to DES-CAT.

This is the subtitle in English (translate if necessary). It is used when two titles appear on the title page. Usually one of these is the specific title, while the other is a description such as Final Report. Technical Report, Progress Report for the Period of ..... etc. The description is alwoys to be entered as the subtitle.

If the document is one volume of a monographic set, (i.e., non-serial set. e.g., a four volume encyclopedia) then the subtitle frequently contains the volume number as well as specific subtitle. In this case, the volume number must be included in the subtitle, abbreviated "Vol." followed by a space, Arabic numerals and a period. E.g., lfrom INIS-15 (Rev. 2014 pt. 3, p. 20)

\section{PHOSPHORUS and its COMPOUNDS}

In Two Volumes

Volume II: TECHNOLOGY. BIOLOGICAL FUNCTIONS, and APPLICATIONS"

becomes [see INIS-15(Rev. O) ${ }^{(14)}$ pt. 2, p. 68]

PT $=$ Phosphorus and its compounds;

$P S=$ Vol. 2. Technology, biological functions, and applications;

If, on the other hand, the volume has no specific subtitle, but only a volume number, then for an analytic of this monographic set, the volume should be entered in the collation (COL - discussed below) along with the page numbers. See, for example, INIS-2 (Rev. $2)^{(i 3)}$ p. 44-45. However, for non-analytic entry covering this entire volume, the volume number should be entered as the subtitle.

Iitl Augmentation (TA) INIS-620 Subordinate to DES-CAT.

In the preparation of a printed subject index, it may be desirable to print the title and subtitle of each article under a given subject heading in order to give the user a more specific indication of the document's contents. Some titles convey insufficient or 
misleading information about the contents of the document. Furthermore certain types of documents such as institutional progress reports may have brief standardized titles which do not reflect the actual subject content of the report. In these cases, title augmentation may be used to provide the essential subject information which was omitted from the title. It may be in the form of descriptors, natural language text, single words. phrases, sentences, formulas, chemical reactions, etc. This information will be printed in the subject index in parentheses immediately following the title and subtitle and should therefore be supplementary to them without any duplication.

Language (L) INIS-600 Subordinate to DES-CAT.

If the document is entirely in English, omit this data element. If it is written in a language other than English, enter the preposition "In" followed by a space and the language for languages, separated by commas). Examples:

L=In Russian;

$L=$ In English, French, German;

Do not surround by parentheses as INIS does. Where multiple bibliographic levels are involved, enter the language at the lowest level only, e.g.. A of AMS as shown in IAEA-INIS-2, p. $45^{(14)}$.

Original Title (OT) INIS-230 Subordinate to DES-CAT.

For non-English dacuments, enter the title here in the original language. Transliterate if necessary using the INIS transliteration rules $^{(7)}$ and the diacritical sign and accert treatment given in Appendix I of the INIS descriptive cataloguing rules $(5)$. However. use the Greek alphabet, diacritical signs, and accents of our full character set insteod of transliterating these.

Journal or Series Title (OT, level S) ISO Standards Subordinate to DES-CAT.

Journal and Series Title are input in abbreviated form according to ISO standards as documented in the Bibliographic Suide for Editors and Author ${ }^{(8)}$. This has been chosen instead of the INIS Authority List for Journal Titles ${ }^{(9)}$ because the former is more complete and because it contains CODEN.

Original Subtitle (OS) INIS-231 Subordinate to DES-CAT.

Always enter this in its original language, following the same rules as for the "Original Title"(OT).

Edition (ED) INIS-250 Subordinate to DES-CAT.

This is used when an edition statement appears on the document which is being encoded, exactly as INIS does. I.e.,

"First edition" is never entered

"Second edition" becomes "ED=2. ed.:"

"third enlarged edition" becomes "ED=3. enlarged ed.:"

This data element is not allowed for reports. Such information is carried in parentheses after the report number (RN).

Journal CODEN (CODEN) Subordinate to DES-CAT.

This is the CODEN as documented in the Bibliographic Guide for Editors and Authors ${ }^{(8)}$. It is a five alphabetic character code with a sixth alphameric check character appended. Enter all six characters. 
Authors Node (AUTHORS) Subordinate to DES-CAT.

This is a pure node data element. It serves to link together a group of authors with their affiliations. All authors (AU below) in a given authors node are associated with all affiliations (AA below) in the same node. An example is given in the "GEODOC INPUT" section above.

\section{Data Elements of AUTHORS Node (within DES-CAT node):}

Authors Name (AU) INIS-100 Subordinate to AUTHORS.

This entry is made up in the following sequence:

a) Surname

b) A comma and a blank followed by initials. Initials are followed by periods and are not separated by blanks. The full forename may be given if there is only one.

c) A blank and other name fragments which are not forenames and which should be transposed to the end of the name according to the Anglo-American Cataloging Rules(10).

Transliterate as described in the original title (OT) section above. See thi INIS rules ${ }^{(5)}$ and the Anglo-American Cataloging Rules $(10)$ for more details on name fragments and on Spanish matronymics (last example below). If the document has no perscinal author $A U$ or corporate entry CE use Anon.

Examples: Morris, A.C.

Koester, L.J. Jr.

Aizawa, Yoshio

Chen, Shin-Hsiung

Lopez-Garcia. A.

Da Fonseca, V.L.

Lo Fontaine. J. de

McCarthy, G.L.

Anon.

Lopez M del C. A.

Author Note (AN) INIS-100 Subordinate to AU.

This can have one of the following four values:

$$
\begin{aligned}
& \text { AN }=\text { ed.; for "editor" } \\
& \text { AN }=\text { eds.; for "editors" } \\
& \text { AN }=\text { comp.; for "compiler" } \\
& \text { AN }=\text { comps.; for "compilers" }
\end{aligned}
$$

If authors, editors, and compilers are in the same author's node, transpose the outhors to the end. Multiple editors for compilersi should be grouped together and the note "eds." (or comps.) should follow the last author to which it applies.

Author Affiliation (AA) INIS-100 Subordinate to AUTHORS.

This is to be standardized according to the INIS Authority List for Corporate Entries and Report Number Prefixes. IAEA-INIS-6(6), if possible. 
Affiliation Code (AC) INIS-700 Subordinate to AA.

This is the seven digit code from IAEA-INIS-6 ${ }^{(6)}$. It should immediately follow the affiliation which it represents. It should not contain imbedded blanks. E.g., $A C=9100234$; . If the affiliation (AA) and its code $(A C)$ are not found in IAEA-INIS-6, one of two procedures should be followed.

The first procedure is needed when you feel that the affiliation should be added to the GRID authority list. Format the name as is described in the preface of IAEA-INIS- 6 . according to COSATI standards(11). In place of the affiliation code use "a" for add, i.e., $A C=a_{i}$. This procedure should be used whenever you think the affiliation will appear more than once or twice.

The second procedure is to be used on affiliations which ore unlikely to appear again, and for which you cannot justify the standardization effort. In this case, enter the affiliation in free form, and enter $A C=x$; which means "not standardized, do not add to the GRID authority list".

Corporate Entry (CE) INIS-110 Subordinate to DES-CAT.

All reports must have a corporate entry. This is standardized like author affiliation (AA) above. It is defined to be either

Corporate Author: the aganization(s) identified as responsible for the intellectual content of the document (in the absence of a personal authar), or

Issuing Body/Assignee: the organizations identified as technically, editorially, or contractually responsible for its contents (in conjunction with a personal author). or the assignee(s) of a patent, or the academic iristitution granting a degree.

Corporate Code (CC) INIS-710 Subordinate to CE.

This is the seven digit code corresponding to the carporate eritry (CE) above. If the corporate entry (CE) and its corporate code (CC) are not found in IAEA-INIS-6 ${ }^{(6)}$. the same procedures as were described for (AA) and $(A C)$ should be followed.

Note on $A A$ and $C E$ : Frequently, the corporate entry(s) (CE) exactly duplicates the authors affiliation(s) (AA) for one of the AUTHORS nodes. In that case. the complete entry is made in $C E$, but is not made in $A A$. Instead, the symbolic notation, $A A=C E$; is used.

For example, in the example given in the GEODOC INPUT section above, suppose the author affiliation given in the first AUTHORS node were also the Corporate Entry. Then the input statements

$A A=$ International Atomic Energy Agency, Vienna (Austria);

$A C=3294000$;

would be replaced by

$A A=C E$;

$\mathrm{CE}=$ International Atomic Energy Agency, Vienna (Austria)

CC=3294000;

Academic Degree (DG) INIS-111 Suburdinate to DES-CAT.

Consists of two parts:

a) Designation of the academic dissertation (Thesis, Thése, Habilitationsschrift. 
etc.) entered according to the Anglo-American Cataloging Rules(10) and followed by a space.

b) Acodemic degree abbreviated according to Webster's New Collegiate Dictionary(12), placed in parentheses.

Sponsor (SPO) Subordinate to DES-CAT.

This is an organization designated as a sponsor of the document or of the work described in it. This should be standardized and handled just as described above for author affiliation (AA).

Sponsor Code (SPC) Subordinate to SPO.

This is the seven digit corporate code from IAEA-INIS- $6^{(6)}$.

Sponsor's Contract Number (SCN) Subordinate to SPO.

This is the contract number.

The sponsor code (SPC) and sponsors contract number (SCN) must follow the appropriate sponsor (SPO), e.g.

$$
\begin{aligned}
& \text { SPC }=\text { USAEC, Washington, D. C.; } \\
& \text { SPC }=6549500 ; \\
& \text { SCN }=W-7405-\text { eng-26; }
\end{aligned}
$$

Report or Patent Number (RN) INIS-300 Subordinate to DES-CAT.

Enter as in the INIS rules ${ }^{(5)}$ :

a) Report number prefix separated from sequence number by double hyphen.

b) Semi-colons and spaces replaced by hyphens.

c) Transliterate letters if necessary.

The prefix letters must represent the responsible corporate body given in the corporate entry (CE). If they do not, write them as given on the report, preceded by the acronym or letter prefix identifying the largest organizational unit. E.g. "International Atomic Energy Agency, Vienna (Austria) STI/PUB/129" should be entered as RN=IAEA-STI/PUB--129;

Edition, revision, or part numbers should be placed in parentheses after the report number, not in the edition tag (ED). E.g.

$$
\begin{aligned}
& \text { RN=TID--22361 (pt.1); } \\
& \text { RN=IAEA-INIS--6 (rev.7); } \\
& \text { RN=TID--11295(ed.4); }
\end{aligned}
$$

For purposes such as these the following abbreviations are to be used:

$\begin{array}{ll}\text { Addendum } & \text { add. } \\ \text { Amendment } & \text { amend. } \\ \text { Appendix } & \text { app. } \\ \text { Book } & \text { bk. } \\ \text { Chapter } & \text { ch. } \\ \text { Edition } & \text { ed. } \\ \text { Number } & \text { no. } \\ \text { Part } & \text { pt. } \\ \text { Revised, Revision } & \text { rev. } \\ \text { Section } & \text { sect. }\end{array}$




\section{$00 \% 04403232$}

$\begin{array}{ll}\text { Series } & \text { ser. } \\ \text { Summary } & \text { summ. } \\ \text { Supplement } & \text { suppl. } \\ \text { Volume } & \text { vol. }\end{array}$

Many report numbers include descriptive words within the number; these wards may either be ignored or abbreviated. The words are ignored when the numbers form one series regardless of the descriptive words; they are abbreviated when there are two or more series of numbers, each associated with a specific group of words. Abbreviations frequently used are:

$\begin{array}{ll}\text { Bulletin } & \text { Bull- } \\ \text { Circular } & \text { Circ- } \\ \text { Contribution } & \text { Contrib- } \\ \text { Memo. } & \text { M- } \\ \text { Memo. report } & \text { MR- } \\ \text { Publication } & \text { Pub- } \\ \text { Reference } & \text { Ref- } \\ \text { Report } & \text { omitted unless issuing organization hos already } \\ & \text { abbreviated to "R-": thus NRL Report } 5414 \text { becomes } \\ \text { Research memo. } & \text { NRL--5414, but the "R" in ARD-R--2117 is retained } \\ \text { Research paper } & \text { RM- } \\ \text { Research report } & \text { RP- } \\ \text { Special report } & \text { RR- } \\ \text { Technical memo. } & \text { SR- } \\ \text { Technical note } & \text { TM- } \\ \text { Technical publication } & \text { TN- } \\ \text { Technical report } & \text { TP- } \\ \text { Technical translation } & \text { TR- } \\ \text { Translaton } & \text { TT- }\end{array}$

If the report is not numbered, enter $R N=$ no number; and the system will assign a number of the form GRID--123. For patent number procedures, see the INIS rules ${ }^{(5)}$ for tog 300 .

Secondary Number (SN) INIS-310 Subordinate to DES-CAT.

Only one number is allowed as a report number (RN). Additional numbers, structured according to the same rules as for report numbers, are to be given here.

International Standard Book Number-ISBN (INT) INIS-320 Subordinate to DES-CAT.

If an ISBN is given it is to be entered as the letters "ISBN" followed by a blank and the ten character code. E.g.

INT=ISBN $047156530 x$;

International Patent Classification Code-IPC (INT) INIS-320 Subordinate to DES-CAT.

For International (or National) Patent Codes, see the INIS rules ${ }^{(5)}$ for $\operatorname{tag} 320$. 
International Standard Serial Number-ISSN (INT) INIS-320 Subordinate to DES-CAT.

When ISSN is introduced", it will be entered here as the letters "ISSN" followed by a blank and the code.

Publisher (PUB) INIS-402 Subordinate to DES-CAT.

The name of the publisher is entered here according to the Anglo-American Cataloging Rules ${ }^{(10)}$, transliterated if necessary. Only one may be given. Choose any one if several are given.

Place of Publication (PUP) INIS-401 Subordinate to DES-CAT.

The place of publication is entered here as cited in the piece of literature according to the Anglo-American Cataloging Rules ${ }^{(10)}$, transliteraled if necessary. If several places of publication are given, enter only the one which corresponds to the name given in (PUB).

Publication Date (PUD) INIS-403 Subordinate to DES-CAT.

The date of publication is given here as

a) The day of the month in arabic numerals.

b) The first three letters of the month (not followed by a period).

c) A four digit year.

Separate these by blanks. A range of months is entered as the first-month; i.e., "January-February 1970" is entered as "Jan 1970". If only the season is given, amit it from the date, but equate Spring to no. 1 , Summer to no. 2 , etc., if no issue number is given, and enter this as the issue number in the collation (COL) described below. If no date exists, enter PUD=[no];.

Collation (COL) INIS-500 Subordinate to DES-CAT.

The discussion given here (including the discussions of Chapter and Volume in the primary title and subtitle sections PT and PS abovel goes beyond that given in the INIS rules ${ }^{5 !}$. The intent here is to remain entirely consistent with INIS, but to clarify the rules where the INIS documentation is unclear or inconsistent. Any actual deviations from INIS practice are unintentional. This data element gives volume and/or page number(s) or the number of pages or volumes for the piece of literature being recorded. Use English equivalents for non-English designations (e.g. v. for Band or Tome; suppl. for Ergänzungsband). Use the abbreviations

$\begin{array}{ll}\text { v. } & \text { for volume(s) } \\ \text { p. } & \text { for page(s) } \\ \text { vp. } & \text { for various pages } \\ \text { no. } & \text { for issue number(s) } \\ \text { pt. } & \text { for part(s) } \\ \text { suppl. } & \text { for supplement(s) }\end{array}$

These abbreviations are to be separated from preceding and trailing numbers by a blank. except within parentheses, where abbreviations and their associated numbers are not separated.

Parentheses are placed around information other than volume and page (e.g. issue, part. or supplement) in journal references. Issue number is placed first, and is followed by a ccmma and a blank if other information follows inside the parentheses. If a volume 
number and an issue number are both present, the abbreviation "no." is omitted. Parentheses are also used in some non-journal references, whenever page numbering is also present.

A range of numbers is indicated by a dash. Two (or more) ranges may be entered, separated by a comma and a blank.

Examples for most types of documents are shown in the following table, along with the INIS-2(13) page number for those cases which correspond to INIS samples. The collation is to be entered on the level indicated by "Entry Level"

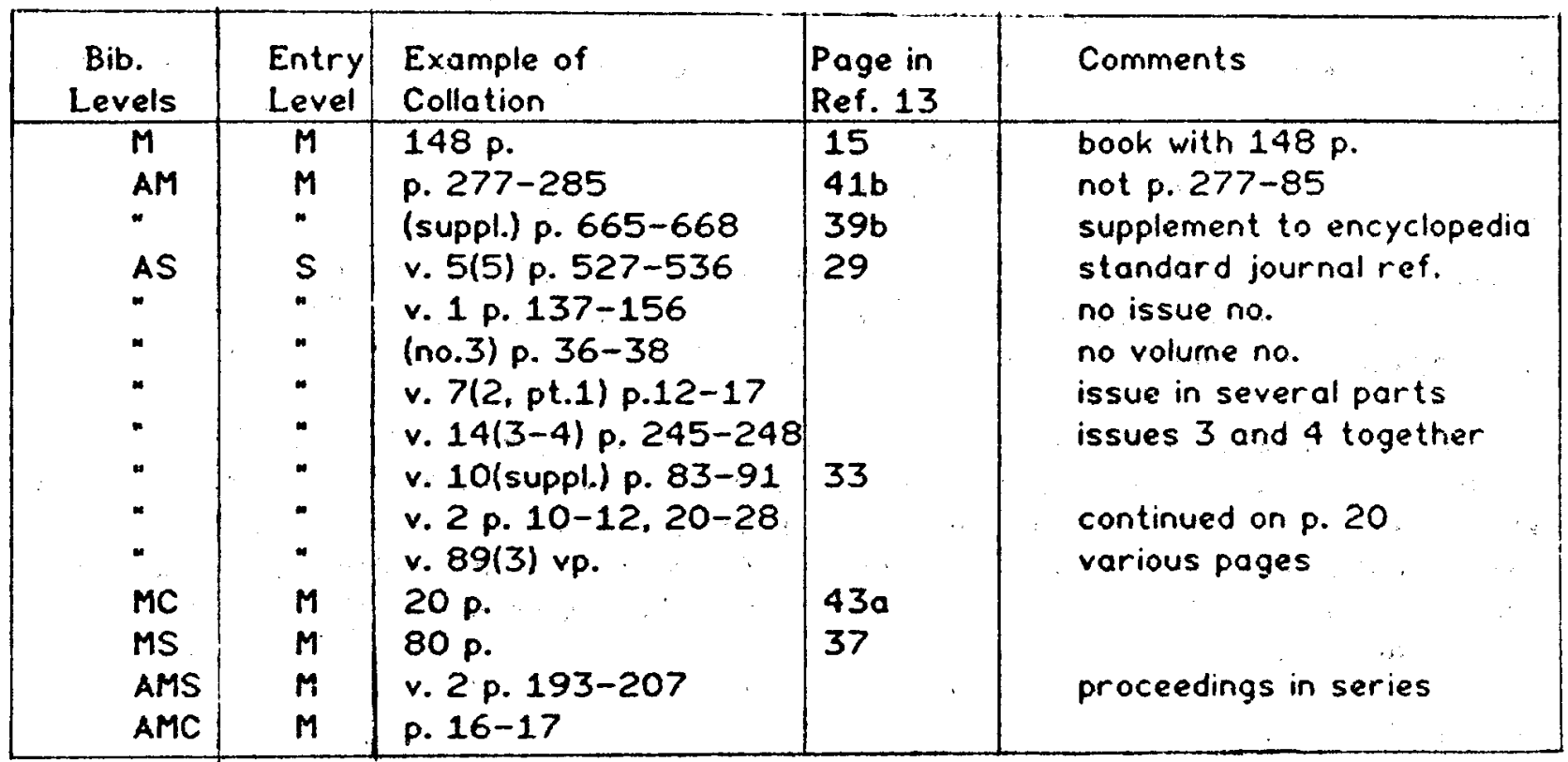

Page numbers should be converted to Arabic numerals, and, if possible, all or dinal numbers should be converted to cardinal numbers (e.g. "Second supplement" would be converted to "suppl. 2"). A book that shows pagination "x. + $132^{n}$ would be entered as "142 p."

Chapter number is never entered here; it is always entered as part of the title" or subtitle, as is discussed in the primary title (PT) section above.

Volume number is usually entered here. However, for monographic entries, not containing an analytic level, the volume number is included in the subtitle, as is discussed in the primary subtitle section above.

Note (N) INIS-610 Subordinate to DES-CAT.

The following entries are mandatory.

Type of Record

D - drawings
C - maps
Mandatory Entry

Enter the scale as a decimal number, e. g.: "Scale 0.00035". 
F - films

H - phonorecordings

$T$ - computer media

Enter the running time, indicate whether film has soundtrack or cclor, and show the nominal width. Example: "19 min. sd. color. $35 \mathrm{~mm} "$ (note sd. = sound)

Enter the running time, e. g. "28 min." If appropriate, indicate the rotation speed for disks and the width for phonotapes.

Enter sufficient data to indicate the requirements necessary to read it. For example, for a 9-track magnetic tape recorded at 800 binary digits per inch, your entry would read " 9 track, 800 bits/in, NRZI".

When you are reporting a short communication one of the following notes must be entered here:

$$
\begin{aligned}
& N=\text { Published in summary form only; } \\
& N=\text { Letter-to-the-editor: }
\end{aligned}
$$

Other mandatory INIS entries are not entered here because the GRID data elements already include them. These are "availability" in AV below and "translation information" in the related reference section (REL-REF) below.

The use of note (N) is not confined to the few obligatory instances just described. Any other significant information that has not been covered by the other data elements should be entered here in free form. For example if you are dealing with o review article which. contains an extensive bibliography, you should have included $Z$ as a literary indicator in record type (TY) above. This can now be expressed quantitatively as a note. which might read simply:

but might be put:

$$
\mathrm{N}=322 \text { refs; }
$$

$\mathrm{N}=$ Cantains a bibliogr aphy of 322 refs. classified by subject:

Similarly you can indicate other interesting contents by notes of the form " 3 drawings", "6 maps", etc. Such notes are not intended to be exhaustive but should be included at your discretion. There are many other possibilities. Use this data element wherever you believe that it would add to the GEODOC file.

Conference Title (COT) INIS-210 Subordinate to DES-CAT.

Whenever the piece of literature being encoded is related to a conference, encode " $K$ " as the literary indicator in the document type (TY) data element discussed above, and enter the conference title, place and date in COT, COP and COD respectively. Enter the title here in its "official" and most complete form, i.e., as assigned by the organizers of the meeting. Translate into English if necessary.

If your piece of literature is one paper published within conference proceedings, the entries COT, COP and COD could apply equally to the $A$ or $M$ level. Enter it at $A$, according to the general rule that when two levels are equally appropriate you use the lowest level. Note: these entrys at the $A$ level are supressed in the final output for conference proceedings (i.e. when $T Y=\ldots / A M / K_{i}$ or $T Y=\ldots / A M S / K_{i}$ ). This avoids repetition of the information in the proceedings title. However, do not omit these entries on input.

Conference Place (COP) INIS-211 Subordinote to DES-CAT. 


\section{4}

The entry here must show at least the city and country (e.g. Paris. France). Other geographic subdivisions larger than city but smaller than ccuntry may also be entered at your own discretion (e.g. Ann Arbor, Mich., USA). For spelling of city names, use the "Pronouncing Gazetteer" of Webster's New Collegate Dictionary (12). Places not listed there are to be shown in the original language, transliterated if necessary. Country names should be standardized according to INIS: Terminology and Codes for Countries and International Organizations ${ }^{(15)}$. If a conference took place in mare than one place, make multiple entries for this data element, e.g.:

COP=Munich; Karlsruhe, F. R. Germany; Vienna, Austria; Trieste, Italy;

Conference Date (COD) INIS-213 Subordinate to DES-CAT.

Enter this in the same way as the publication date (PUD) described above. If a range of dates is given, enter only the beginning date.

Avallability and Price (AV) INIS-213 Subordinate to DES-CAT.

Examples:

$A V=$ Available from University Microfilms, Inc., Ann Arbor, Mich.:

$A V=$ Free on application to the U. S. Geological Survey, Washington, D.C. 20244;

No policy decision with regard to NTIS or INIS availability has yet been made.

Related Reference Node (REL-REF) INIS-006-007-610 Subordinate to DES-CAT. The use of this node is mandatory for translations and for non-English journals which are also published later in cover-to-cover translations. It can also be used for any relationship to other documents which you may wish to express. It is a generalization of INIS tags 006,007 and 610. It contains data elements RL, RLR, RSC

Relator (RL) INIS-006 Subor dinate to REL-REF.

If your piece of literature is a transiation, you must enter:

$R L=T$;

For any other relationship, enter a slash:

$R L=/$;

Relationship and/or Reference (RLR) Subordinate to REL-REF.

For a translation ( $R L=T$;) relevant details of the original citation must be given, inclusing the reference. Examples:

RLR=Translated from Nippon Genshiryoku Gakkai-Shi, v. 13(4) p. 19-20 (Apr 1970);

RLR $=$ Translation of "Materia e Antimateria", Milano, Mondadori, 1961 Translated from Russion;

For other relationships $(R L=/ ;)$ describe the relationship in free form, referring to the related document(s) by reference.

Note: When you report an article from a journal which is also published at a later date in the from of a cover-to-cover translation journal, you must enter the following:

$R L=/$;

RLR $=$ for English translation see the journal.....

(give the abbreviated English title of the journal as cited in the Bibliographic Guide for Editors and Authors ${ }^{(8)}$. 
Related Short Code (RSC) Subordinate to REL-REF.

The short code of the related reference is given here. If both types of relators $(T$ and /) are used for the same document, put the translation first, e.g.

REL-REF.1;

$R L=T$;

RLR $=$ Geol. Geokhim. 23(6), 147(1972);

RSC = Bumashnov 72;

REL-REF.2;

$\mathrm{RL}=/$;

$R L R=T h i s$ article gives results in disagreement with Geol. Zh. 17(9). 42(1970);

RSC $=$ Ermolov 70 ;

The REL-REF nodes are not normally explicitly input, but are created when RL is input.

\section{Abstract Node (ABSTRACT)}

Each abstract node contains one abstract (ABS) and one or more abstract source (ABSO). There may be more than one abstract node.

Abstract (ABS) Subordinate to ABSTRACT.

Abstract in English, translated if necessary. Paragraph breaks are ignored.

Abstract Source (ABSO) Subordinate to ABSTRACT.

If the abstract is unchanged from the authors except for paragraphing. use

$A B S O=$ auth;

If the abstract has been altered (e.g. shortened) but has not been completely rewritteri, enter two sources:

$A B S O=$ auth; IJK;

where IJK is the initials of the person who altered the abstract.

If the author abstract is left intact but augmented, put the abstract and the augmentation into two separate abstract nodes, e.g..

ABSTRACT.1;

$A B S=\ldots$. text of abstract...;

$A B S O=$ auth;

ABSTRACT.2;

$A B S=$...text of augmentation...:

$A B S O=I J K$;

This will appear in the printed output as follows:

...text of abstract...(auth)...text of augmentation...(IJK).

The augmentation should therefore be supplementary to the abstract and without any duplication.

\section{Index Node (INDEX)}

This node contains all indexing information. If the document is subdivided, the general analysis goes into INDEX.1 while the splits (subdivisions) 90 into INDEX.2, INDEX.3, etc. See the discussion of splits and the example below for more details. See also the INIS Manual for Indexing $(1)$ for more discussion of this and other indexing topics.

Category/Qualifier (CQ) Subordinate to INDEX. 
This is the GRID category/qualifier. If more than one category/qualifier is input, the category must be repeated with each qualifier, even if it is unchanged, e.g $\mathrm{CQ}=$ Exploration/Geochemistry; Exploration/Geophysics;

Appendix II lists the allowed category/qualifiers.

IIC Category (TICC) Subordinate to INDEX.

This is the 6 digit ERDA Technical Information Center Category, entered without blanks. e.g.,

TICC $=150301 ; 150302$;

Enter at the mnat specific level applicable, i.e. do not enter the more general categories 150000 or 150300 in the above case because their presence is implied by the presence of one or more of their subcategories.

Descriptor (DE) INIS-800 Subordinate to INDEX.

This data element is for the descriptors which you have decided best describe your piece of literature. The descriptors must be selected from the Geothermal Thesaurusi16!. Enter only the descriptors from the most specific level applicable: presence of the broader terms is implied.

Data Descriptors (DD) Subordinate to INDEX.

Enter those thesourus descriptors which describe the actual numerical or graphical jato contained in this paper. Use the same rules as were given for $D E$ above. Some or all of these data descriptors may duplicate the descriptors entered as DE. Other data descriptors (DD) may not appear as DE because the numerical data which they describe forms an insignificant part of the subject content of the article.

Identifier (ID) Subordinate to INDEX.

This is for free (uncontrolled vocabulary) descriptors. It is not to be used when you believe that the identifier should be in the thesaurus. It cannot be searched.

Proposed Descriptor (PD) INIS-810 Subordinate to. INDEX.

If you encounter information which cannot be adequately described by the descriptors given in the latest version of the thesourus, invent a descriptor and use it as an ordinary thesaurus descriptor in DE or DD. You must also enter the proposed descriptor here at PD. Once this record has been entered into the GEODOC file, you may use your proposed descriptor just like an ordinary descriptor, even before it is approved by the Thesaurus manager(16).

\section{Discussion of INDEX Splits with Example:}

Most documents should have only one index node (INDEX.1). For retrieval purposes, all descriptor and categroy information in INDEX.1 is considered to apply to the whole document.

Some documents can be more effectively indexed by subdividing the document into sections for indexing purposes. Each section can be indexed separately. The indexing information for each section should be placed in a separate INDEX node, beginning with INDEX.2. The INDEX.1 node is always reserved for indexing information which applies to the whole document. As an example, consider Uchiyama 70, Geothermics, Spec. Iss. 2, v. 2 (pt. 2) p. $1572-1580$ (1970): 
INDEX.1;

$C Q=U$ tilization/Power Production;

TICC $=150900$;

$D E=$ Matsukawa geothermal field; Japan; geothermal power plants; steam

INDEX.2; power plants;

$C Q=$ Exploration/Geochemistry;

TICC $=150904$;

$\mathrm{DE}=$ steam;

$\mathrm{DD}=$ pressure; flow rate; temperature; gas content; hydrogen sulfide;

INDEX.3: carbon dioxide:

$C Q=P$ hysical Chemistry/Corrosion;

TICC=150903;

$D E=$ steam; alloys; thermal water; $\mathrm{Cr}-$ Mo-V steel; stainless steel 41 ; SUS 50 alloy; NBsBl alloy; DCul-H alloy;

$\mathrm{DD}=$ corrosion;

INDEX.4;

$C Q=$ Exploration/Geochemistry;

TICC =150302;

$\mathrm{DE}=$ thermal water; chemical analysis;

$\mathrm{DD}=\mathrm{pH}$; potassium; sodium; calcium; magnesium; iron; aluminum; silicic acid $\left(\mathrm{H}_{2} \mathrm{SiO}_{3}\right)$; chloride; sulfate; carbonic acid $\left(\mathrm{H}_{2} \mathrm{CO}_{3}\right)$; hydragen sulfide; boric INDEX.5; acid;

$\mathrm{CQ}=$ Reservoir Characterizotion/Piping;

TICC $=150902$;

$D E=$ steam transmission; steam pipes; pipeline courses; diameter; thickriess; thermal expansion; corrosion;

$\mathrm{DD}=$ steam pressure losses;

\begin{abstract}
A search request for all documents containing dato on "flow rate" at "Motsuhawa geothermal field" would recover this document because INDEX.1 information applies to the whole document and therefore can be linked with the information from any section of the document; in this case INDEX.2. However, a search raquest for all documents containing information on the "chemical analysis" of " $\mathrm{Cr}-\mathrm{Mo}-\mathrm{V}$ steel" would not recover this document because INDEX.3 and INDEX.4 apply to separate sections of the document and cannot be linked.
\end{abstract}

\title{
Control Node (CONTROL)
}

The data elements contained in the control node are for GRID internal bookkeeping and control of GRID data files. They are not normally displayed to users. These data elements are as follows:

Local Availability (LA) Subordinate to CONTROL.

Location of local (LBL) hard copy, e.g. LA=GRID library;. The local availability (LA) indicates ownership. If you borrow the hard copy. leave LA unchanged but insert the following subordinate data element: 
Borrow/Roturn (BR) Subordinate to LA.

For example: LA=K. Mirk; BR=Borrowed by JJH 7 Jan 75 . Return by 1 Feb.;

Descriptive Cataloging Source (DCSO) Subordinate to CONTROL.

Descriptive Cotalogers initials, a blank followed by a date in standard form and optional comment.

Abstracting and Indexing Source (AISO) Subordinate to CONTROL.

Abstractor-Indexer initials followed by a date and optional comment. If the abstracting or indexing are updated, add another AISO keeping the previous entry as well. Examples:

AISO.1=FPH 7 Apr 1975;

AISO.2=FPH 21 Sep 1975 augmented abstract;

Data-File (DATA-FILE) Subordinate to CONTROL.

This contains the file name of a GRID numerical data file. It is added to the GEODOC record to indicate that the numerical data file contains or should contain data from this document.

\section{Data Descriptor for Potential Data (POT) Subordinate to DATA-FILE.}

This contains data descriptors to describe the specific kinds of data from this document which should be in the named data file.

Data Descriptor for Included Data (IN) Subordinate to DATA-FILE.

This cantains the data descriptor(s) for those data which are already included in the flle named above. For example:

DATA-FILE=well;

POT=steam sample data; isotopic data;

IN=isotopic data;

\section{ACKNOYLEDGEMENTS}

The development of this document file has involved the cooperative efforts of many people and groups.

We wish to express our appreciation for the many invaluable discussions and interactions with J. Herr and G. Haire (Information Research Group. LBL), and for the gerierous assistance given us by many individuals of the ERDA Office of Public Affairs. Technical Information Center, Oak Ridge. TN, and Holifield National Latoratory.

We have also benefitted greatly from the close cooperation with $D$. Richards and $A$. Rit tenberg (Particle Data Group, LBL) and M. Lederer (Table of Isotopes Project. LBL) on systems development.

We also wish to acknowledge useful discussions with S. Schwartz and J. Stakes (LBL). N. Crow and D. Elchesen (Technical Information Department, LLL). 


\section{References}

1) David R. Richards (LBL), Berkeley DBMS, Particle Data Group Internal Memo PDG-2000 (DRR 11 NOV 1975 or later version).

2) M. Leavitt and C. M. Lederer, Overview of IRATE-Interactive Retrieval and Text Editor, LBL-4607, September 1975.

3) A. Allen and B. Armstrong, (LBL), How to Get Along with an IRATE Terminal, October 1974.

4) The IRATE character set contains numbers, upper case and lower case Roman letters with font control to change from normal characters to italics, boldface bold italics, or Greek characters. In addition many special characters are available, including overwriting characters such as umlauts $(\ddot{a})$, underlined $(a)$ and vector arrows $(\vec{a})$.

5) International Atomic Energy Agency, Vienna (Austria), INIS: DESCRIPTIVE CATALOGUING RULES, IAEA-INIS-1 (Rev.2), June 1972.

6) International Atomic Energy Agency, Vienna (Austria), INIS: AUTHORITY LIST FOR CORPORATE ENTRIES AND REPORT NUMBER PREFIXES, IAEA-INIS-6 (ReV.7), MaY 1974.

7) International Atomic Energy Agency, Vienna (Austria). INIS: TRANSLITERATION RULES FOR SELECTED NON-ROMAN CHARACTERS, IAEA-INIS-10 (Rev.1), March 1971.

8) Biosciences Information Service of Biological Abstrocts, Chemical Atstracts Service, and Engineering Index, Inc., BIBLIOGRAPHIC GUIDE FOR EDITORS AND AUTHORS, American Chemical Society, Washington, D. C., 1974.

9) International Atomic Energy, Agency, Vienna (Austria), INIS: AUTHORITY LIST FOR JOURNAL TITLES, IAEA-INIS-11 (Rev.3), June 1974.

10) American Library Association, ANGLO-AMERICAN CATALOGING RULES. Prepared by the American Library Association. The Library of Congress, the Library Association and the Canadian Library Association. North American text. Chicago, 1967. 400 p.

11) U.S. Committee on Scientific and Technical Information (COSATI), STANDARD FOR DESCRIPTIVE CATALOGING OF GOVERNMENT SCIENTIFIC AND TECHNICAL REPCRTS, PB-173314.

12) WEBSTER'S NEW COLLEGIATE DICTIONARY, Latest ed. Springfield, Mass. Merriam.

13) International Atomic Energy Agency, Vienna (Austria), INIS: DESCRIPTIVE CATALOGUING SAMPLES. IAEA-INIS-2 (Rev.2), June 1972.

14) International Atomic Energy Agency, Vienna (Austria), INIS: SELF-TEACHING MANUAL FOR DESCRIPTIVE CATALOGUERS. IAEA-INIS-15 (Rev.0), September 1972. 


\section{$00,0440: 257$}

15) International Atomic Energy Agency, Vienna (Austria), INIS: TERMINOLOGY AND CODES FOR COUNTRIES AND INTERNATIONAL ORGANIZATIONS. IAEA-INIS-5 (ReV.2), July 1971.

16) The Geothermal Thesaurus is being prepared by Jessie Herr (Information Research Group, LBL) in cooperation with GRID-LBL, and ERDA-TIC.

17) International Atomic Energy Agency, Vienna (Austria), INIS: MANUAL FOR INDEXING, IAEA-INIS-12 (Rev.2), January 1974. 
Table I. OEODOC Data Elements

\begin{tabular}{|c|c|c|c|c|}
\hline $\begin{array}{l}\text { LBL } \\
\text { Tag }\end{array}$ & $\begin{array}{l}\text { INIS } \\
\text { Tag }\end{array}$ & $\mathrm{m}^{*}$ & $n^{*}$ & Data Element Definition \\
\hline \begin{tabular}{l} 
SC \\
TY \\
DES-CAT \\
BL \\
PT \\
PS \\
TA \\
L \\
OT \\
OS \\
ED \\
CODEN \\
AUTHORS \\
AU \\
\multicolumn{1}{c}{ AN } \\
CE AC \\
CC \\
DC \\
SPO \\
SPC \\
SCN \\
RN \\
SN \\
INT \\
PUB \\
PUP \\
PUD \\
COL \\
N \\
COT \\
COP \\
COD \\
AV
\end{tabular} & $\begin{array}{l}300 \\
310 \\
320 \\
402 \\
401 \\
403 \\
500 \\
610 \\
210 \\
211 \\
213\end{array}$ & $\begin{array}{l}m \\
m\end{array}$ & $n$ & $\begin{array}{l}\text { document short code: unique identifier for document } \\
\text { type of document/bibliographic levels/literary indicator } \\
\text { delineates information for one bibliographic level } \\
\text { bibliographic level indicator } \\
\text { primary title (translated into English if necessary) } \\
\text { primary subtitle (translated into English if necessary) } \\
\text { title augmentation } \\
\text { language (for non-English document) } \\
\text { original titie (non-English) or journal/series title } \\
\text { original subtitle (non-English) or journal/series subtitle } \\
\text { edition } \\
\text { journal coDEN } \\
\text { delineates author-affiliation group } \\
\text { author's name } \\
\text { author note (ed., comp., eds., comps.) } \\
\text { author's affiliation } \\
\text { affiliotion code } \\
\text { corporate entry } \\
\text { corporate code } \\
\text { academic degree } \\
\text { sponsor } \\
\text { sponsor code } \\
\text { sponsor contract number } \\
\text { report or potent number } \\
\text { secondary numbers } \\
\text { International Stondard Book Number or Patent Code } \\
\text { publisher } \\
\text { place of publication } \\
\text { publication date } \\
\text { collation (volume, issue, page) } \\
\text { note } \\
\text { conference title } \\
\text { conference place } \\
\text { conference date } \\
\text { availability and price }\end{array}$ \\
\hline
\end{tabular}

Continued on next page. 
Table I. OEODOC Data Elements (Continued)

\begin{tabular}{|c|c|c|c|c|}
\hline $\begin{array}{l}\operatorname{LBL} \\
\operatorname{Tag}\end{array}$ & $\begin{array}{l}\text { INIS } \\
\text { Tag }\end{array}$ & m* & $\mathbf{n}$ & Data Element Definition \\
\hline $\begin{array}{l}\text { REL-REF } \\
\text { RL } \\
\text { RLR } \\
\text { RSC } \\
\text { ABSTRACT } \\
\text { ABS } \\
\text { ABSO } \\
\text { INDEX } \\
\text { CQ } \\
\text { TICC } \\
\text { DE } \\
\text { DD } \\
\text { ID } \\
\text { PD } \\
\text { CONTROL } \\
\text { LA } \\
\text { BR } \\
\text { DCSO } \\
\text { AISO } \\
\text { DATA-FILE } \\
\text { POT } \\
\text { IN }\end{array}$ & $\begin{array}{l}800 \\
800 \\
m \\
810\end{array}$ & $\begin{array}{l}m \\
m \\
m \\
m \\
m \\
m \\
m\end{array}$ & $n$ & $\begin{array}{l}\text { delineates information for one related reference. } \\
\text { reletor } \\
\text { relationship and reference } \\
\text { related short code } \\
\text { delineates one abstract } \\
\text { abstract } \\
\text { abstract source } \\
\text { INDEX.1 general indexing. INDEX.2, } 3, . . N \text { splits } \\
\text { category/qualifier } \\
\text { TIC category } \\
\text { descriptor from thesaurus } \\
\text { data descriptor from thesaurus } \\
\text { identifier } \\
\text { proposed descriptor } \\
\text { internal LBL data elements } \\
\text { local availability } \\
\text { berrow/return } \\
\text { descriptive catalogers initials, date and comment } \\
\text { abstractor-indexers initials, date and comment } \\
\text { data file name } \\
\text { data descriptor for potential data } \\
\text { data descriptor for included data }\end{array}$ \\
\hline
\end{tabular}

"m-This data dement may have multiple entries.

"n-This data lement contains no value and need not be entered on input. It serves to delineate a group of data elements. 
Fi g. 1 OEODOC Record Structure

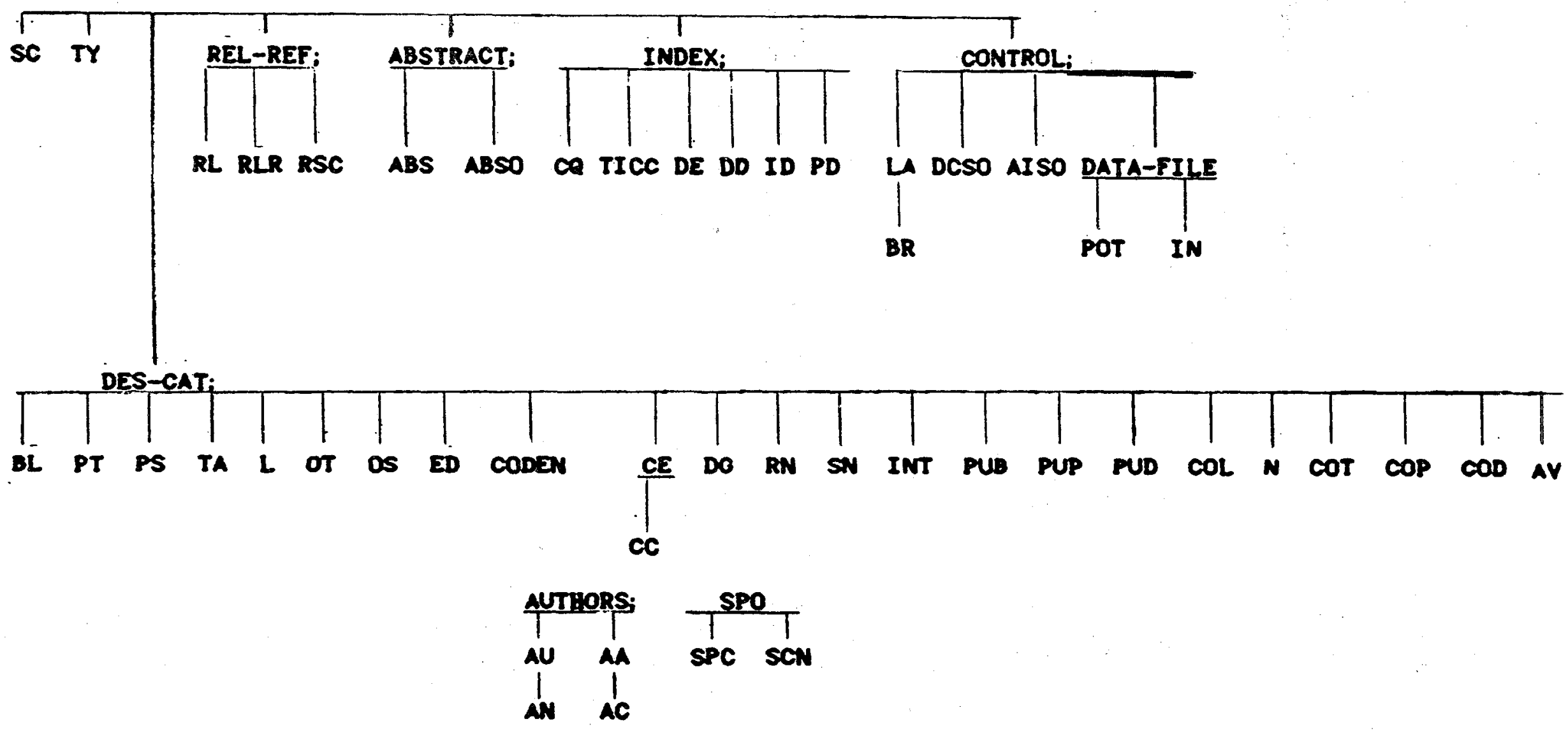






\section{FOOTNOTES TO MATRIX OF BIBLIOGRAPHIC DATA ELEMENTS:}

$X$ Indicates that the corresponding data element must always be entered for the associated type of record. Indicates that the corresponding data element must be entered if present on the document being cataloged. Indicates that the corresponding data element is optional and to be used at the discretion of the encoder Indicates that the corresponding data element is optional and to be used at the corresponding data element is never entered for the associated type of record.

For reports the edition is entered as part of the report number.

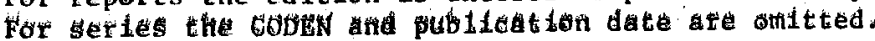

Either author or corporate entry tust be given.

The code in brackets must be present whenever these data elements are used.

For series the number of the series, if given is entered here.

For documents related to a conference these data elements are required.

For translations and for. non-english journals which are published later in cover-to-cover translations these data elements must be present.

WHEN IDENTICAL ENTRIES WOULD OCCUR IN MULTI-LEVEL RECORDS ENTER ONLY AT THE MOST APPROPRIATE LEVEL. IN CASES WHERE IDENTICAL ENTRIES AT TWO LEVELS ARE EQUALLY APPROPRAITE, ENTER ONLY AT THE LOWEST LEVEL. 
GEODOC Category/Qualifier Authority List

Category

Exploration

Physical Chemistry

Environmental

Utilization

Institutional

Reservoir Characterization
Qualifier

Geology

Geochemistry

Geophysics

Hyd rology

Evaluation

Land-Use Factors

Solutions

Gases

Minerals

Silica

Working Fluids

Heat Transport Materials

Corrosion

Scaling

Rock-Solution Interactions

Subsidence

Seismicity

Noise

Water Mixing

Land-Use Factors

$\mathrm{H}_{2} \mathrm{~S}$

$\mathrm{NH}_{3}$

Metals

Hot Water Transport

Space Heating

Process Heat

Agricultural Heat

Power Production

Corrosion

Scaling

Evaluation

Binary Cycle Power

Land-Use Factors

Exploration and Production

Operating Regulations

Financial Incentives

Power Sales

Fluid Transport

Legislation

Porosity

Artificial Stimulation

Natural Recharge

Artificial Recharge

Modeling

Well Tests and Measurements

Piping 
This report was prepared as an account of work sponsored by the United States Government. Neither the United States nor the United States Energy Research and Development Administration, nor any of their employees, nor any of their contractors, subcontractors, or their employees, makes any warranty, express or implied, or assumes any legal liability or responsibility for the accuracy, completeness or usefulness of any information, apparatus, product or process disclosed, or represents that its use would not infringe privately owned rights. 